\title{
Stent anchor technique to reduce microcatheter loop for stent-assisted coiling of anterior communicating artery aneurysm
}

\author{
Kunal Vakharia, MD, ${ }^{1,3}$ Stephan A. Munich, MD, ${ }^{1,3}$ Michael K. Tso, MD, PhD, ${ }^{1,3}$ \\ Muhammad Waqas, MBBS, ${ }^{1,3}$ and Elad I. Levy, MD, MBA ${ }^{1-4}$ \\ Departments of ${ }^{1}$ Neurosurgery and ${ }^{2}$ Radiology, Jacobs School of Medicine and Biomedical Sciences, University at Buffalo; \\ ${ }^{3}$ Department of Neurosurgery, Gates Vascular Institute at Kaleida Health, Buffalo; and ${ }^{4}$ Canon Stroke and Vascular Research \\ Center, University at Buffalo, New York
}

Stent-assisted coiling offers a potential solution for coil embolization of broad-based aneurysms. Challenges associated with navigating a microcatheter beyond these aneurysms sometimes require looping the microcatheter within the aneurysm dome. Reducing microcatheter loops within domes can be difficult, and anchor techniques have been described, including balloon anchor, stent-retriever anchor, and stent anchor techniques. The authors present a patient requiring stent-assisted coiling of an anterior communicating artery aneurysm in whom a stent anchor technique was used to reduce a microcatheter loop within an aneurysm dome before coil embolization. Postembolization angiographic runs showed complete coil occlusion of the aneurysm with approximately $35 \%$ packing density.

The video can be found here: https://youtu.be/zHR1ZOArUro.

KEYWORDS stent anchor; Low-profiled Visualized Intraluminal Support (LVIS) stent (MicroVention); anterior communicating artery aneurysm; coil embolization; video 